\title{
Maximal respiratory pressures in adult Chinese, Malays and Indians
}

\author{
A. Johan*, C.C. Chan*, H.P. Chia**, O.Y. Chan+, Y.T. Wang*
}

Maximal respiratory pressures in adult Chinese, Malays and Indians. A. Johan, C.C. Chan, H.P. Chia, O.Y. Chan, Y.T. Wang. CERS Journals Ltd 1997.

ABSTRACT: Maximal static inspiratory and expiratory mouth pressures ( $P$ I,max and $P E$,max, respectively) enable the noninvasive measurement of global respiratory muscle strength. The aim of this study was primarily to obtain normal values of $P I$, max and $P$ E,max for adult Chinese, Malays and Indians and, secondarily, to study their effect on lung volumes in these subjects.

Four hundred and fifty two healthy subjects (221 Chinese, 111 Malays, 120 Indians) were recruited. Measurements of $P \mathrm{I}$,max from residual volume (RV), $P \mathrm{E}$, max from total lung capacity (TLC) and forced vital capacity (FVC) were obtained in the seated position.

There were significant ethnic differences in $P_{I}, \max$ and $P E$,max measurements obtained in males, and FVC measurements in both males and females. Chinese males had higher $P$ I,max values (mean $( \pm \mathrm{SD}) 88.7 \pm 32.5 \mathrm{cmH}_{2} \mathrm{O}$ ) and higher $P E$,max values (113.4 \pm 41.5) than Malay males $\left(P I, \max 74.0 \pm 22.7 \mathrm{cmH}_{2} \mathrm{O}, P\right.$ E,max $\left.94.7 \pm 23.4 \mathrm{cmH}_{2} \mathrm{O}\right)$. Chinese males had higher $P$ E,max than Indian males $\left(P I, \max =83.7 \pm 30.0 \mathrm{cmH}_{2} \mathrm{O}\right.$, $P E, m a x$ 98.4 $\pm 29.2 \mathrm{cmH}_{2} \mathrm{O}$ ). There were no significant differences among Chinese females $\left(P I, \max 53.6 \pm 20.3 \mathrm{cmH}_{2} \mathrm{O}, P \mathrm{E}\right.$,max $\left.68.3 \pm 24.0 \mathrm{cmH}_{2} \mathrm{O}\right)$, Malay females $(P I$, max $\left.50.7 \pm 18.3 \mathrm{cmH}_{2} \mathrm{O}, P E, \max 63.6 \pm 21.6 \mathrm{cmH}_{2} \mathrm{O}\right)$ and Indian females $\left(P_{I}\right.$, max $50.0 \pm 15.2$ $\mathrm{cmH}_{2} \mathrm{O}, P \mathrm{P}, \max 60.7 \pm 20.4 \mathrm{cmH}_{2} \mathrm{O}$ ). In both sexes, the Chinese had a higher FVC compared with Malays and Indians. After adjusting for age, height and weight, race was still a determinant for $P E$,max in males, and FVC in both sexes. The FVC only correlated weakly with $P I$,max and $P E$,max in both sexes.

Ethnic differences in respiratory muscle strength, and lung volumes, occur among Asians. However, respiratory muscle strength does not explain the differences in lung volumes in healthy Asian subjects.

Eur Respir J 1997; 10: 2825-2828.

Maximal static mouth pressures provide a simple noninvasive method to assess respiratory muscle strength. Maximal static inspiratory and expiratory mouth pressures $(P I$, max and $P$ E,max, respectively) have been studied and reported for healthy adults [1-3], adolescents [4] and the elderly [5-7] in Caucasians. In small studies, respiratory muscle strength in Asians appears lower than Caucasians $[8,9]$. To our knowledge, there has been no large study of $P \mathrm{I}$,max and $P$ E,max in Asians. The primary objective of this study was to define normal values of $P \mathrm{I}$,max and $P$ E,max in adult Chinese, Malays and Indians.

The determinants of lung function in different ethnic groups have been postulated to be due to differences in respiratory muscle strength, lung recoil, airway-alveolar differential growth, chest wall compliance and chest wall dimensions $[10,11]$. As a secondary objective, we analysed the effect of respiratory muscle strength on lung volumes in Asian subjects. Forced vital capacity (FVC) was used as a surrogate measurement [12] for total lung capacity (TLC).

\section{Methods}

\section{Subjects}

Four hundred and fifty two healthy adults (221 Chinese, 111 Malays and 120 Indians), aged 20-80 yrs were includ-
*Dept of Respiratory Medicine, Tan Tock Seng Hospital, Singapore. **Dept of Community, Occupational and Family Medicine, National University of Singapore. ${ }^{+}$Dept of Industrial Health, Ministry of Labour, Singapore.

Correspondence: C.C. Chan

Dept of Respiratory Medicine

Tan Tock Seng Hospital

Moulmein Road

Singapore 308433

Keywords: Asians

lung function

lung volumes

maximal static mouth pressures

normal values

Received: April 91997

Accepted after revision August 311997 ed. They included teachers, office workers, manual workers in factories, health workers (doctors, nurses, attendants) and retired persons. All were nonsmokers or had smoked less than 400 cigarettes in their lifetime, and had normal chest radiographs within 6 months of testing. None had any history of cardiopulmonary disease, regular medication or known exposure to respiratory irritants or allergens.

\section{Pulmonary function testing}

Age was recorded as at the last birthday, standing height was recorded barefoot in centimetres, and weight was recorded in light clothing without shoes to the nearest $0.1 \mathrm{~kg}$. All lung function tests were performed with the subject seated.

Maximum static inspiratory and expiratory mouth pressures were measured using Ashcroft pressure gauges (Ashcroft, USA) according to the method of BLACK and HyAтT [6]. A flanged mouthpiece was used rather than a tube at the mouth. Noseclips were applied prior to each manoeuvre and a small leak was allowed to prevent glottic closure. The subjects were instructed to exhale to residual volume (RV) or inhale to TLC before attempting to inhale or exhale maximally against an occluded mouthpiece to obtain $P \mathrm{I}$,max and $P \mathrm{E}, \max$, respectively. Inspiratory or expiratory effort was sustained for at least $1 \mathrm{~s}$. As these tests were concerned with maximal functions, the largest 
pressures recorded were used. The tests were not interrupted until the three highest pressures recorded were comparatively similar and the subject considered him or herself unable to perform better. The measurements were carried out by two designated technicians. After appropriate coaching, the best of three technically acceptable attempts was recorded in centimetre of water.

Maximum expired spirograms were obtained using a dry rolling spirometer (9000IV; Gould Recording Systems Division, Dayton, OH, USA). Each subject had to do the test three times with at least a 1 min interval between each test. The best of three technically acceptable tests was used to determine FVC. All volumes were corrected to body temperature, ambient pressure and saturated with water vapour (BTPS).

\section{Statistical analysis}

Values are expressed as mean $\pm \mathrm{SD}$, unless otherwise stated. The coefficient of variation $(\mathrm{CV})$ for $P \mathrm{I}$,max and $P \mathrm{E}$,max in each subject, defined as the SD divided by the mean of the best three attempts was obtained and expressed in percentage. One way analysis of variance (ANOVA) was used to compare anthropometric data (age, height and weight), maximal static mouth pressures $(P \mathrm{I}, \max$ and $P$ E,max $)$ and lung volumes (FVC) in the various ethnic groups. Subsequent multiple pairwise comparisons between ethnic groups were done using Bonferroni's t-tests where ANOVA showed statistically significant differences. Pearson's correlation was used to test for correlation of lung volume and maximal static mouth pressure with anthropometric data, and of lung volume with maximal static mouth pressure. Multiple regression analysis was performed to assess the contributions of age, height and weight to the ethnic differences in $P \mathrm{I}$,max, $P \mathrm{E}$,max and $\mathrm{FVC}$. Multiple linear regression equations were obtained for $P \mathrm{I}$,max and $P$ E,max as dependent variables and age, height and weight as independent variables. A p-value of 0.05 or less was considered to be significant.

Table 1. - Anthropometric data for all subjects

\begin{tabular}{lccccccc}
\hline & \multicolumn{3}{c}{ Male } & & \multicolumn{3}{c}{ Female } \\
\cline { 2 - 3 } \cline { 6 - 8 } & Chinese & Malay & Indian & & $\begin{array}{c}\text { Chinese } \\
(\mathrm{n}=90)\end{array}$ & $\begin{array}{c}\text { Malay } \\
(\mathrm{n}=42)\end{array}$ & $\begin{array}{c}\text { Indian } \\
(\mathrm{n}=43)\end{array}$ \\
\hline Age yrs & $40.8 \pm 13.4$ & $37.3 \pm 11.5$ & $39.1 \pm 11.5$ & & $38.9 \pm 11.8$ & $33.4 \pm 9.6$ & $35.1 \pm 11.8$ \\
Height cm & $167.0 \pm 7.0$ & $163.9 \pm 6.3$ & $166.3 \pm 6.4$ & & $156.6 \pm 5.5$ & $154.8 \pm 5.0$ & $155.2 \pm 6.5$ \\
Weight kg & $64.1 \pm 9.8$ & $64.3 \pm 11.3$ & $67.2 \pm 11.6$ & & $53.6 \pm 9.2$ & $57.8 \pm 14.0$ & $55.7 \pm 11.2$ \\
\hline
\end{tabular}

Values expressed as mean $\pm S \mathrm{D}$.

Table 2. - Mouth pressures and lung volumes in Chinese, Malays and Indians

\begin{tabular}{|c|c|c|c|c|c|c|}
\hline & \multicolumn{3}{|c|}{ Male } & \multicolumn{3}{|c|}{ Female } \\
\hline & Chinese & Malay & Indian & Chinese & Malay & Indian \\
\hline$P \mathrm{I}, \max \quad \mathrm{cmH}_{2} \mathrm{O}$ & $\begin{array}{r}88.7 \pm 32.5 \\
(83.1-94.3)\end{array}$ & $\begin{array}{r}74 \pm 22.7 \\
(68.5-79.5)\end{array}$ & $\begin{array}{c}83.7 \pm 30 \\
(78.9-90.5)\end{array}$ & $\begin{array}{c}53.6 \pm 20.3 \\
(49.3-57.9)\end{array}$ & $\begin{array}{c}50.7 \pm 18.3 \\
(45.0-56.4)\end{array}$ & $\begin{array}{c}50.0 \pm 15.2 \\
(45.3-54.7)\end{array}$ \\
\hline$P$ E,max $\mathrm{cmH}_{2} \mathrm{O}$ & $\begin{array}{c}113.4 \pm 41.5 \\
(106.0-121.0)\end{array}$ & $\begin{array}{c}8.7 \\
94.7 \pm 23.4 \\
(89.1-100.0)\end{array}$ & $\begin{array}{c}9.6 \\
98.4 \pm 29.2 \\
(91.8-105.0)\end{array}$ & $\begin{array}{c}9.8 \\
68.3 \pm 24.0 \\
(63.3-73.3)\end{array}$ & $\begin{array}{c}11.5 \\
63.6 \pm 21.6 \\
(56.9-70.3)\end{array}$ & $\begin{array}{c}13.2 \\
60.7 \pm 20.4 \\
(54.4-67.0)\end{array}$ \\
\hline & 7.3 & 6.8 & 7.4 & 8.9 & 10.7 & 10.9 \\
\hline FVC L & $\begin{array}{r}3.7 \pm 0.8 \\
(3.6-3.8)\end{array}$ & $\begin{array}{r}3.3 \pm 0.6 \\
(3.2-3.4)\end{array}$ & $\begin{array}{r}3.2 \pm 0.6 \\
(3.1-3.3)\end{array}$ & $\begin{array}{c}2.7 \pm 0.6 \\
(2.6-2.8)\end{array}$ & $\begin{array}{c}2.4 \pm 0.4 \\
(2.3-2.5)\end{array}$ & $\begin{array}{c}2.4 \pm 0.6 \\
(2.2-2.6)\end{array}$ \\
\hline
\end{tabular}

Values expressed as mean $\pm S D$, with $95 \%$ confidence intervals in parenthesis and mean within-subject coefficient of variation expressed as a percentage. PI,max: maximal inspiratory mouth pressure; $P \mathrm{E}$,max: maximal expiratory mouth pressure; FVC: forced vital
The anthropometric data are as shown (table 1). There were significant differences in the height among the races in males $(\mathrm{p}=0.004)$, and in age $(\mathrm{p}=0.023)$ and height $(\mathrm{p}=$ 0.028 ) among the races in females. Chinese males were, on average, taller than Malay males $(\mathrm{p}=0.003)$. In addition, Chinese females were, on average, older $(\mathrm{p}=0.023)$ and taller $(\mathrm{p}=0.028)$ than Malay females.

The results of maximum static mouth pressures and the lung volumes are as shown (table 2). The mean within subject $\mathrm{CV}$ for the best three attempts of $P \mathrm{I}$,max and $P$ E,max were similar in the different ethnic groups (table 2 ). As expected, males had higher mean values compared with females, and $P$ E,max was higher than $P \mathrm{I}$,max.

There were significant ethnic differences in $P \mathrm{I}, \max (\mathrm{F}=$ 5.676, $\mathrm{p}=0.004)$ and $P \mathrm{E}, \max (\mathrm{F}=8.328, \mathrm{p}<0.0001)$ in males, and significant ethnic differences in FVC in males $(\mathrm{F}=$ $12.198, \mathrm{p}<0.001)$ and females $(\mathrm{F}=4.770, \mathrm{p}=0.01)$. Multiple pairwise comparisons using Bonferroni's t-test gave the following results. Chinese males had a higher PI,max than Malay males $(\mathrm{p}=0.003)$ and a higher $P \mathrm{E}$,max than both Malay ( $\mathrm{p}=0.001)$ and Indian males $(\mathrm{p}=0.008)$. Chinese males had a higher FVC compared with Malay males $(p=0.007)$ and Indian males $(\mathrm{p}<0.0001)$. For females, there were no significant ethnic differences in mouth pressures. Chinese females had a higher FVC compared with Malay females $(\mathrm{p}=$ 0.043) and Indian females ( $\mathrm{p}=0.036)$.

Race was still a determinant for $P$ E,max $(\mathrm{p}=0.001)$, but not for $P \mathrm{I}, \max (\mathrm{p}=0.059)$ in males after adjusting for age, height and weight. Race was also still a determinant of FVC, both in males $(\mathrm{p}<0.0001)$ and females $(\mathrm{p}=0.003)$ after adjusting for age, height and weight.

Mouth pressures correlated weakly $(\mathrm{r}=-0.16-0.27, \mathrm{p}<$ 0.05 ) with age, height and weight in males and with age in females (table 3 ). The multiple regression equations for $P \mathrm{I}$,max and $P$ E,max are as shown (table 4$).$

Overall, FVC also correlated weakly with $P$ I,max in both males $(\mathrm{r}=0.31, \mathrm{p}<0.001)$ and females $(\mathrm{r}=0.30, \mathrm{p}<0.001)$, and with $P$ E,max in males $(\mathrm{r}=0.39, \mathrm{p}<0.001)$ and females

expressed as a percentage. PI,max: maximal inspiratory mouth pressure; PE, max: maximal expiratory mouth pressure; FVC: forced vital 
Table 3. - Correlations of lung function with anthropometry

\begin{tabular}{|c|c|c|c|c|c|c|}
\hline & \multicolumn{3}{|c|}{ Male } & \multicolumn{3}{|c|}{ Female } \\
\hline & Age (yrs) & Height (cm) & Weight (kg) & Age (yrs) & Height (cm) & Weight $(\mathrm{kg})$ \\
\hline$\overline{\mathrm{FVC} \mathrm{L}}$ & $-0.50(<0.001)$ & $0.63(<0.001)$ & $0.20(<0.001)$ & $-0.48(<0.001)$ & $0.53(<0.001)$ & 0.10 (N S) \\
\hline$P \mathrm{I}, \max \mathrm{cmH}_{2} \mathrm{O}$ & $-0.18(0.003)$ & $0.18(0.003)$ & $0.20(0.001)$ & $-0.16(0.03)$ & 0.11 (N S) & 0.03 (N S) \\
\hline$P$ E,max $\mathrm{cmH}_{2} \mathrm{O}$ & $-0.18(0.003)$ & $0.27(<0.001)$ & $0.18(0.002)$ & $-0.18(0.02)$ & 0.04 (N S) & -0.04 (N S) \\
\hline
\end{tabular}

Values are expressed as Pearson's correlation coefficient with the p-value in parenthesis. N s: nonsignficant. For further definitions see legend to table 2 .

Table 4. - Multiple linear regression equations for $P_{\mathrm{I}, \text { max }}$ and $P_{\mathrm{E}, \text { max }}$

\begin{tabular}{|c|c|c|}
\hline & $P \mathrm{I}, \max \mathrm{cmH}_{2} \mathrm{O}$ & $P$ E, max $\mathrm{cmH}_{2} \mathrm{O}$ \\
\hline Chinese males & $\begin{array}{c}37.24-0.67 \mathrm{~A}+0.15 \mathrm{H}+0.85 \mathrm{~W} \\
(\mathrm{r}=0.405)\end{array}$ & $\begin{array}{c}-106.17-0.52 \mathrm{~A}+1.05 \mathrm{H}+1.03 \mathrm{~W} \\
(\mathrm{r}=0.420)\end{array}$ \\
\hline Chinese females & $\begin{array}{c}68.80-0.49 \mathrm{~A}-0.05 \mathrm{H}+0.22 \mathrm{~W} \\
(\mathrm{r}=0.263)\end{array}$ & $\begin{array}{c}112.14-0.59 \mathrm{~A}-0.11 \mathrm{H}-0.07 \mathrm{~W} \\
(\mathrm{r}=0.293)\end{array}$ \\
\hline Malay males & $\begin{array}{c}151.32-0.33 \mathrm{~A}-0.55 \mathrm{H}+0.38 \mathrm{~W} \\
(\mathrm{r}=0.219)\end{array}$ & $\begin{array}{c}109.82+0.05 \mathrm{~A}-0.22 \mathrm{H}+0.30 \mathrm{~W} \\
(\mathrm{r}=0.146)\end{array}$ \\
\hline Malay females & 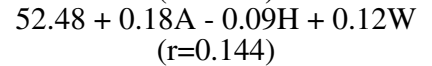 & $\begin{array}{c}181.87-0.16 \mathrm{~A}-0.90 \mathrm{H}+0.43 \mathrm{~W} \\
(\mathrm{r}=0.242)\end{array}$ \\
\hline Indian males & $\begin{array}{c}112.47-0.31 \mathrm{~A}-0.31 \mathrm{H}+0.51 \mathrm{~W} \\
(\mathrm{r}=0.191)\end{array}$ & $\begin{array}{c}-13.66-0.62 \mathrm{~A}+0.79 \mathrm{H}+0.06 \mathrm{~W} \\
(\mathrm{r}=0.331)\end{array}$ \\
\hline Indian females & $\begin{array}{c}54.65-0.48 \mathrm{~A}-0.01 \mathrm{H}+0.24 \mathrm{~W} \\
(\mathrm{r}=0.339)\end{array}$ & $\begin{array}{c}130.36-0.49 \mathrm{~A}-0.40 \mathrm{H}+0.17 \mathrm{~W} \\
(\mathrm{r}=0.251)\end{array}$ \\
\hline
\end{tabular}

A: age (yrs); H: height (cm); W: weight (kg). For further definitions see legend to table 2.

Table 5. - Comparison of Asian and Caucasian values for $P \mathrm{l}$,max and $P_{\mathrm{E}, \max }$

\begin{tabular}{|c|c|c|c|}
\hline $\begin{array}{c}\text { Subjects } \\
\text { n }\end{array}$ & $\begin{array}{c}P \mathrm{I}, \max \\
\mathrm{cmH}_{2} \mathrm{O}\end{array}$ & $\begin{array}{l}P \text { E,max } \\
\mathrm{cmH}_{2} \mathrm{O}\end{array}$ & $\begin{array}{l}\text { First author, } \\
\text { Year, [Ref.] }\end{array}$ \\
\hline \multicolumn{4}{|l|}{$\overline{\text { Male }}$} \\
\hline 277 & $84 \pm 2$ & $105 \pm 2$ & Present study \\
\hline 325 & $113 \pm 2$ & $154 \pm 5$ & LeECH 1983 [1] \\
\hline 80 & $106 \pm 3$ & $148 \pm 4$ & WIL SON 1984 [2] \\
\hline 46 & $105 \pm 4$ & $140 \pm 6$ & VIN C KEN 1987 [13] \\
\hline \multicolumn{4}{|l|}{ Female } \\
\hline 175 & $52 \pm 1$ & $65 \pm 2$ & Present study \\
\hline 480 & $71 \pm 1$ & $94 \pm 1$ & LeECH 1983 [1] \\
\hline 87 & $74 \pm 2$ & $93 \pm 2$ & WIL S O N 1984 [2] \\
\hline 60 & $70 \pm 3$ & $89 \pm 3$ & VIN C Ken 1987 [13] \\
\hline
\end{tabular}

Values are expressed as mean \pm SEM. For definitions see legend to table 2 .

$(\mathrm{r}=0.32, \mathrm{p}<0.001)$. The FVC correlated with $P$ I,max $(\mathrm{r}=0.41$, $\mathrm{p}<0.001)$ and $P \mathrm{E}, \max (\mathrm{r}=0.46, \mathrm{p}<0.001)$ in Chinese males, and $P$ E, $\max (\mathrm{r}=0.28, \mathrm{p}=0.012)$ in Indian males. Among the females, FVC correlated with $P \mathrm{I}$,max $(\mathrm{r}=0.29$, $\mathrm{p}=0.006)$ and $P$ E,max $(\mathrm{r}=0.32, \mathrm{p}=0.002)$ in Chinese, and FVC correlated with $P \mathrm{I}, \max (\mathrm{r}=0.33, \mathrm{p}=0.034)$ and $P \mathrm{E}, \max (\mathrm{r}=0.33, \mathrm{p}=$ 0.031 ) in Indians.

Compared with previously published data $[1,2,13]$, we found that Asian (Chinese, Malay and Indian) values for $P$ I,max and $P$ E,max are generally lower than Caucasian values (table 5).

\section{Discussion}

Singapore is unique as there are three different ethnic groups living in the same environmental and socioeconomic conditions, thus enabling minimization of these confounding factors [12], in comparing differences in lung function. To the best of our knowledge, this is the first large study of maximal respiratory pressures in Asians. Furthermore, it is the first direct comparison between ethnic groups showing an actual difference in respiratory muscle strength. We found that for the same age, height and weight, Chinese males had higher expiratory muscle strength $(P E, \max )$ compared with Malay and Indian males. Chinese males also appeared to have higher inspiratory muscle strength $(P \mathrm{I}, \max )$ compared with Malay males but ethnic differences for $P \mathrm{I}$,max were nonsignificant $(\mathrm{p}=0.059)$ after adjusting for age, height and weight.

Significant correlations were found between maximal respiratory pressures with age, height and weight in males, but only with age in females. However, the correlation coefficients obtained were generally low. LEECH et al. [1] studied 924 healthy Caucasian adults and found that respiratory pressures were significantly positively correlated to weight, but not to height or age. WiLson et al. [2] found that there was significant correlation with age in adult males and height in adult females. However, other studies have obtained conflicting results with age $[5,6]$. The confounding factors that could have resulted in the variability in the measurement of maximal respiratory pressures are: the temporal course of the pressure generated; air leaks at the nose and mouth; motivation; and number of attempts recorded. These factors have been adequately discussed by SмYTн et al. [4].

SchoEnBerg et al. [14] found that weight affected lung function values most. They suggested that the lung function increment with weight was due to increasing muscle bulk. However, further increases in weight due to obesity results in decreasing lung function. They labelled this effect of weight on lung function the "muscularity-obesity effect". The lower maximal respiratory pressures recorded in our study may be attributed to the lower weights reflecting lower muscle bulk in Asians as compared to Caucasians. However this argument cannot explain why there were ethnic differences in $P \mathrm{I}$,max and $P$ E,max in the present male population, as they had similar weights and presumably similar muscle bulk.

Similar environmental and socioeconomic conditions among the ethnic groups in Singapore should have the 
same effect on the functional development of their respiratory system. Yet even after adjusting for age, height and weight, there were significant ethnic differences in respiratory muscle strength and lung volumes in normal adults. Development of maximum static respiratory pressures depends not only on the strength and co-ordination of the respiratory muscles, but also on the motivation and cooperation of the patient. Our subjects were equally motivated and the mean within-subject $\mathrm{CV}$ of $P$ I,max and $P$ E,max were similar in the different ethnic groups. Therefore, motivation and co-operation were not confounding factors in our study. Although endurance training can affect respiratory muscle strength [15], this is an unlikely explanation in our subjects, none of them were highly trained athletes. Therefore, the reasons for ethnic differences in lung function is not apparent in our study. Possible reasons include ethnic differences in sitting height, arm span and chest wall geometry.

To investigate the effect of respiratory muscle strength per se on lung volumes, we used FVC as a surrogate marker for TLC. POLGAR and Weng [12] showed an association between TLC and FVC, and SCHWARTZ et al. [16] had used FVC as a proxy for TLC in his study of race and sex differences in lung function. Despite the obvious ethnic differences in respiratory muscle strength (predominantly $P$ E,max) and lung volumes (FVC) in males, there were only weak correlations between FVC and $P$ E,max. Furthermore, although there were obvious ethnic differences in lung volumes in females, there were no ethnic differences in respiratory muscle strength. Lung elastic recoil in Chinese subjects has previously been shown to be similar to that in Caucasians [17] and by extrapolation should be the same in different ethnic groups. Therefore, respiratory muscle strength and lung elastic recoil do not determine lung volumes in healthy Asian subjects. Other determinants such as chest wall geometry and compliance may have greater influence on normal lung volumes.

Although we found that respiratory muscle strength did not affect lung volume in the healthy subjects, this does not mean that it does not affect lung volume in all subjects. The relationship is not linear and the small decrease in PI,max does account for the small decrease in vital capacity in patients with neuromuscular disease, unlike healthy subjects. Conversely, large increases in PI,max over $50-60 \%$ pred can account for minimal increase in vital capacity. Thus, respiratory system characteristics and respiratory muscle force define lung volume.

The limitation of our study is that we compared Asian values indirectly with Caucasian values in the literature [1, $3,13]$ and not by direct comparison in our laboratory. This is not ideal because the authors use different techniques in different studies. In particular, the type of mouthpiece used greatly influences the result [18]. We used a flanged mouthpiece, which is more universally applicable and commonly used in pulmonary function laboratories. However, the values obtained with a flanged mouthpiece are lower compared with a rubber tube mouthpiece [18]. Nevertheless, using a standard technique [6] and by comparing with studies which used a similar flanged mouthpiece $[1,2,13]$, we found that our values were lower than Caucasian values. Normal values reported by BLACK and HyATT [6] and RINGQVIST et al. [3] were even higher, but a comparison with their values would be inappropriate as they used a rubber tube mouthpiece.
In conclusion, maximal respiratory pressures are generally lower in healthy adult Asians compared with adult Caucasians. Ethnic differences in respiratory muscle strength also occur among Asians. Chinese males have the highest maximal respiratory pressures (maximal expiratory mouth pressure) and the highest lung volumes (forced vital capacity). However, ethnic differences in respiratory muscle strength cannot explain the ethnic differences in lung volumes in healthy adult Asians.

\section{References}

1. Leech JA, Ghezzo H, Stevens D, Becklake MR. Respiratory pressures and function in young adults. Am Rev Respir Dis 1983; 128: 17-23.

2. Wilson SH, Cooke NT, Edwards RHT, Spiro SG. Predicted normal values for maximal respiratory pressures in Caucasian adults and children. Thorax 1984; 39: 535-538.

3. Ringqvist $\mathrm{T}$. The ventilatory capacity in healthy subjects: an analysis of causal factors with special reference to the respiratory forces. Scan J Clin Lab Invest 1966; 18 (Suppl. 88): 1-179.

4. Smyth RJ, Chapman KR, Rebuck AS. Maximal inspiratory and expiratory pressures in adolescents: normal values. Chest 1984; 86: 568-572.

5. McElvaney G, Blackie S, Morrison NJ, Wilcox PG, Fairbarn MS, Pardy RL. Maximal static respiratory pressures in the normal elderly. Am Rev Respir Dis 1989; 139: 27-81.

6. Black LF, Hyatt RE. Maximal respiratory pressures: normal values and relationship to age and sex. Am Rev Respir Dis 1969; 99: 696-702.

7. Enright PL, Kronmal RA, Manolio TA, Schenker MB, Hyatt RE. Respiratory muscle strength in the elderly: correlates and reference values. Am J Respir Crit Care Med 1994; 149: 430-438.

8. Wang YT, Poh SC. Lung function and respiratory muscle strength after propranolol in thyrotoxicosis. Aust NZ J Med 1986; 16: 496-500.

9. Chan CC, Cheong TH, Wang YT, Poh SC. Transdiaphragmatic pressure in young adult Singaporeans - normal values and a comparison between different respiratory manoeuvres. Aust NZ J Med 1996; 26: 75-81.

10. Woolcock AJ, Colman MH, Blackburn CRB. Factors affecting normal values for ventilatory lung function. $\mathrm{Am}$ Rev Respir Dis 1972; 106: 692-709.

11. American Thoracic Society. Lung tunction testing: selection of reference values and interpretative strategies. Am Rev Respir Dis 1991; 144: 1202-1218.

12. Polgar G, Weng TR. The functional development of the respiratory system. Am Rev Respir Dis 1979; 120: 625-695.

13. Vincken W, Ghezzo H, Cosio MG. Maximal static respiratory pressures in adults: normal values and their relationship to determinants of respiratory function. Bull Eur Physiopathol Respir 1987; 23: 435-439.

14. Schoenberg JB, Beck GJ, Bouhuys A. Growth and decay of pulmonary function in healthy blacks and whites. Respir Physiol 1978; 33: 367-393.

15. Leith DE, Bradley M. Ventilatory muscle strength and endurance training. J Appl Physiol 1978; 41: 508-516.

16. Schwartz JD, Katz SA, Fegley RW, Tockman MS. Sex and race differences in the development of lung function. Am Rev Respir Dis 1988; 138: 1415-1421.

17. Chan CC, Cheong TH, Poh SC, Wang YT. Lung elastic recoil in normal young adult Chinese compared with Caucasians. Eur Respir J 1995; 8: 446-449.

18. Koulouris N, Mulvey DA, Laroche CM, Green M, Moxham J. Comparison of two different mouthpieces for the measurement of $P \mathrm{I}, \max$ and $P \mathrm{E}, \max$ in normal and weak subjects. Eur Respir J 1988; 1: 863-867. 